\title{
Synthesis of ppy-MgO-CNT nanocomposites for Ultraviolet application
}

\author{
kumanan Bharathi yazhini ${ }^{1}$, xin wang $^{1}$, Brim Stevy ${ }^{1}$, and Qixing Zhou ${ }^{1}$ \\ ${ }^{1}$ Nankai University
}

April 28, 2020

\begin{abstract}
Cotton is one of the most important raw materials for textile and clothing production. Compared with some synthetic polymer fibers, the main drawback of cotton fibers is its poor mechanical properties and its high flammability, and therefore it cannot be used for special textiles. Cotton fabrics treated with modern flame-retardant and reinforcement finishes often cannot meet rigid military specifications. polypyrrole-Magnesium oxide (ppy-MgO) and polypyrrole-Magnesium oxide-Carbon nanotube (ppyMgO-CNT) composites were prepared with various weight ratios by in-situ chemical polymerization method. 1, 2, 3, 4-butane tetracarboxylic acid (BTCA) was used as cross-linking agent in presence of sodium hypophosphite (SHP). The composite sol was coated on cotton fabric using pad-dry-cure technique. The coated cotton fabrics were characterized by SEM, EDAX, XRD, UV-DRS and FT-IR analysis and tested for flame retardant and UPF application. It was found that ppy-MgO-CNT composite was found to be efficient.
\end{abstract}

\section{Hosted file}

manuscript.rtf available at https://authorea.com/users/309257/articles/440211-synthesis-of-ppymgo-cnt-nanocomposites-for-ultraviolet-application 


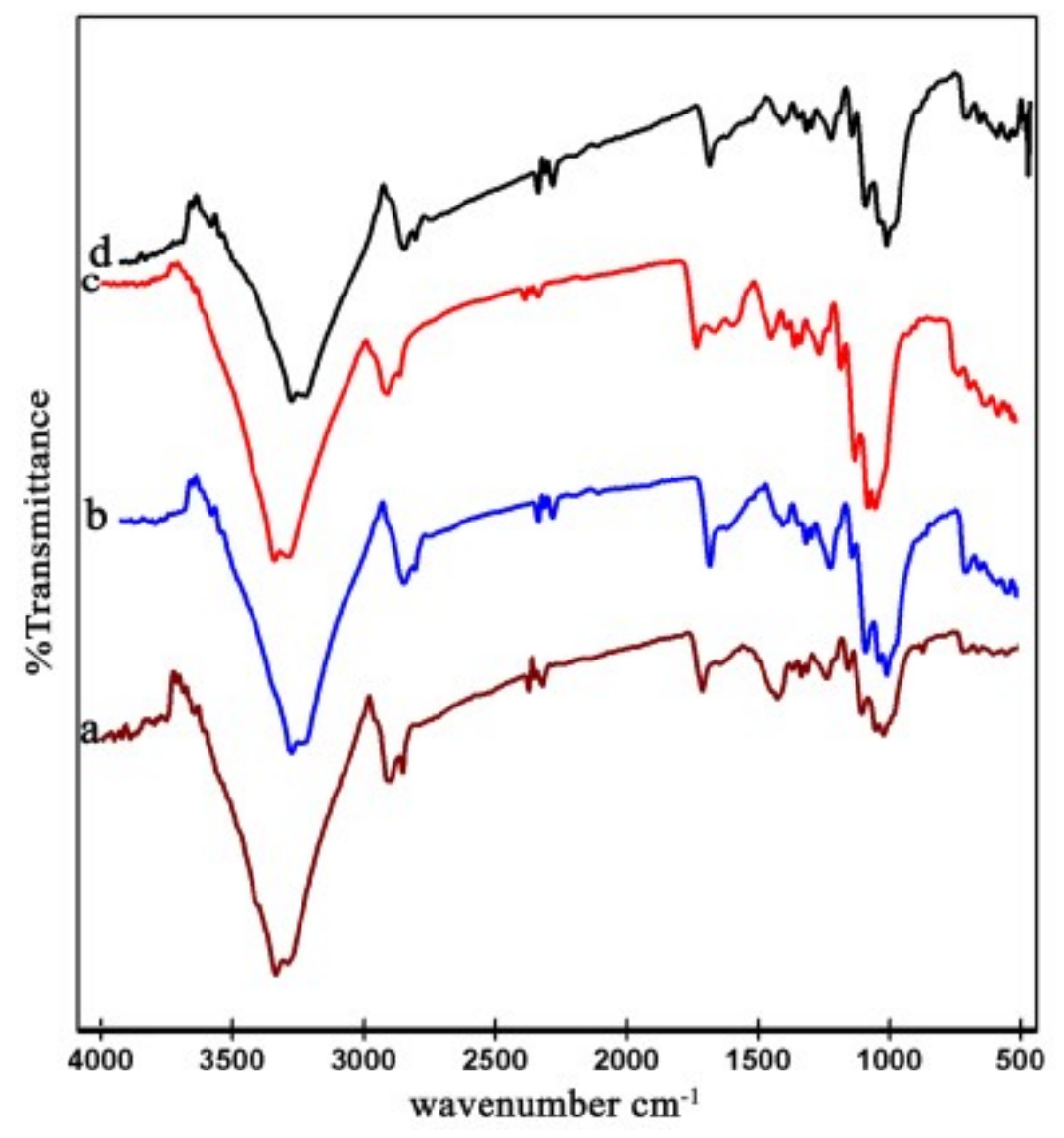




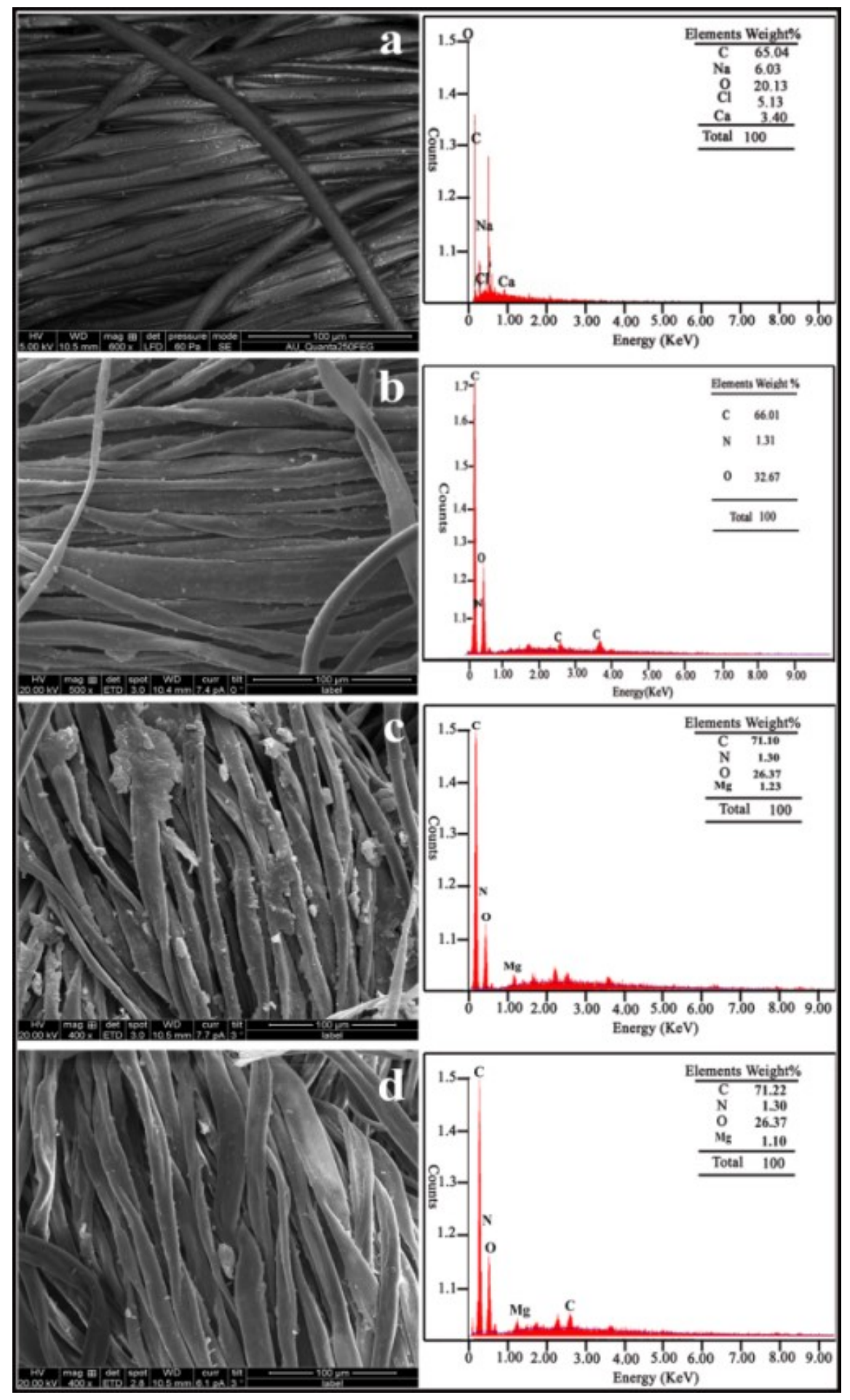




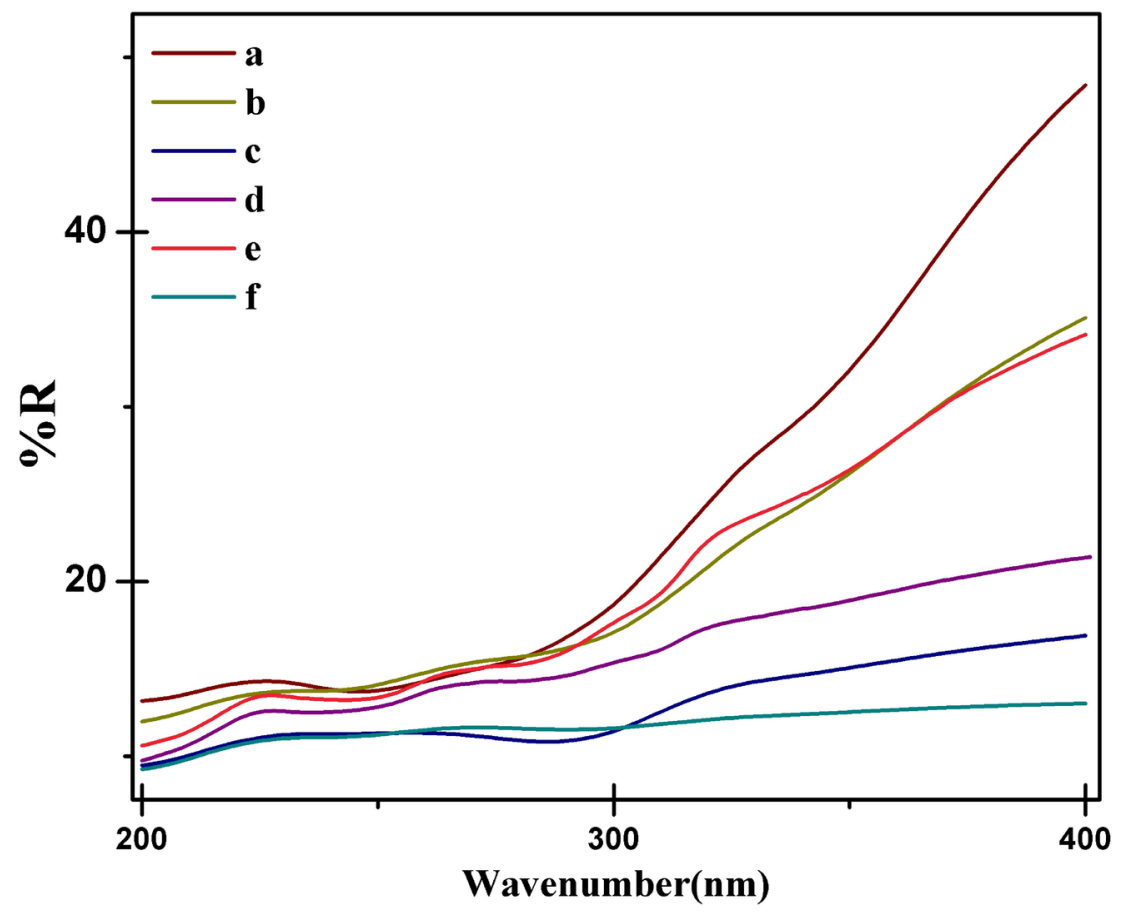

